\title{
Quantitative Real-time PCR using Lactobacilli as Livestock Probiotics
}

Yeon Jae Choi, Sun Ho Kim, Min Jeong Gu, Han Na Choe', Dong Un Kim², Sang Bum Cho², Su Ki Kim ${ }^{3}$ Che Ok Jeon ${ }^{4}$, Gui Seok Bae ${ }^{5}$ and Sang Seok Lee*

Department of Animal Science \& Techndogy, Sunchon National University, Sunchon 540-742, Korea

${ }^{1}$ Depart of Biology, Sunchon National University, Sunchon 540-742, Korea

${ }^{2}$ National Institute of Animal Science, RDA, Suwon 441-706, Korea

${ }^{3}$ Division of Animal Life Science, Konkuk University, Seoul 143-701, Korea

${ }^{4}$ Department of Life Sciences, ChungAng University, Seoul 156-756, Korea

${ }^{5}$ Department of Animal Science \& Technology, ChungAng University, 456-756, Korea

Received November 20, 2010 /Accepted November 23, 2010

\begin{abstract}
This study was conducted using quantitative real-time PCR using Lactobacilli as probiotics. Quantitative real-time PCR (RT PCR) was conducted via a method involving SYBR Green 1 and a probe. Plasmid DNA was cloned using the 16S-23S rRNA intergenic species region. Gene clones were diluted from $10^{2}$ to $10^{10}$. Standard curves were constructed via $\mathrm{Ct}$ values obtained from the results of Real-time PCR via the aforementioned SYBR Green 1 and probe method. Plasmid DNA was also cloned using the 16S-23S rRNA intergenic species region and the gene clones were diluted from $10^{2}$ to $10^{10}$ copy numbers via the probe method. Using RT PCR, a standard curve of plasmid DNA copy numbers was also determined. The slope value for the $Y$-axis intercept and $R^{2}$ value were measured as $-3.346,33.18$, and 0.993 , respectively, via the first method. For the second method, the slope value for the $\mathrm{Y}$-axis intercept and $\mathrm{R}^{2}$ were $-3.321,31.10$ and 0.995 , respectively. The PCR inhibitor could not express the detection curve at a copy number over $10^{10}$ via either method, owing to high DNA density. The DNA extract from probiotics was diluted without pre-culturing, and 16 products were amplified via both methods. The Ct value was 11.06 18.12 in the first method and 16.74 22.11 in the second method. Measured probiotics and log copy values were largely similar among the methods used. It was concluded that both methods are effective for analysis, but further research will be required to verify the optimal method.
\end{abstract}

Key words : DFM, gene cloning, Lactobacillus, probe, real-time PCR

\section{서 론}

Probiotics는 그리스 어원의 'for life'의 뜻을 가진 생균을 의미하며 장내의 미생물 군집의 균형에 도움을 주는 미생물과 그 미생물이 생산한 대사산물을 포함한다 $[2,19]$. 국내에서 생 균제로 가장 많이 사용되고 있는 미생물은 Lactobacillus, Bifidobacterium, Enterococcus와 같은 유산균이며, 효모, 곰팡이, Bacillus sp. 등이 주로 가축용으로 사용되고 있다. 현재 국내에 유통되고 있는 생균제는 수의과학검역원에서 허가를 취득한 동물약품 생균제와 각 시 · 도에 등록한 보조사료 생균제 제품 군으로 분류할 수 있다. 동물용 의약품 생균제의 경우 미생물 의 성분, 함량 및 균수측정, 임상시험과 독성, 안정성 시험 등 을 거쳐 허가를 취득하며, 보조사료 생균제는 각 시 - 도에서 관리하며 신청 시 업체가 지정한 사설연구기관에서 측정한 균수가 최소 $10^{6} \mathrm{CFU} / \mathrm{g}$ 이상이면 허가를 취득한다[13,15].

*Corresponding author Tel : +82-61-750-3237, Fax : +82-61-750-3230

E-mail : rumen@sunchon.ac.kr
이를 검증하기 위한 방법으로 식품공전 및 사료공정서에 등재된 표준 시험법에 따라 증균 배양과 선택배지를 이용한 방법을 사용하고 있다. 그러나 표준 시험법인 배지법은 여러 배양단계와 생화학적 확인검사를 거쳐야 하므로 결과를 얻기 까지 많은 시간과 노동력이 소요되며 위양성(false positive reaction)이나 위음성(false negative reaction)의 결과를 얻을 수 있는 단점이 있다[20]. 따라서 이러한 표준 시험법을 개선하고 보완하기 위한 추가적인 검출법이 요구되는 실정이며, 신속하 고 정확한 검출을 위하여 면역 기법이나 유전자 기법을 활용 한 검출법의 활용이 증가하고 있다[10]. 여러 기법 중 특히 Real time PCR 기법은 가장 빠르고 신뢰성 있는 방법으로 알 려져 있다[4,17]. 이 방법은 기존의 PCR과는 달리 전기영동의 과정이 필요 없이 유전자의 증폭 시 증가되는 형광을 모니터 상에서 실시간으로 관찰 할 수 있다는 장점이 있다[16]. 따라서 전기영동에 의한 오염을 줄이고 검출 시간을 줄일 수 있으며 정량적인 분석까지 가능하다. 또한 검출한계가 이론상 1 $\mathrm{CFU} / 25 \mathrm{~g}$ 인 매우 민감한 방법으로 검출 가능하다[3,10,14]. 이러한 신속 검출법이 표준방법의 대체 방법으로 사용되기 위해서는 검사방법의 공인 평가 및 검증 과정을 거쳐 국제적 
신뢰도와 공정성이 확보 되어야 하며, 신속키트법과 표준법을 비교 검증하는 연구가 활발히 진행되고 있는 상황이다 $[5,21,22]$. 본 연구는 가축용 생균제 제품을 신속하고 정확하게 검증하기 위하여 일반적인 배지법 및 Real-time PCR을 이용 하여 가축용 생균제의 유산균 정량-정성 분석 및 비교 분석 하였다.

\section{재료 및 방법}

\section{정량분석용 표준균주 및 배양}

본 실험에서 사용된 표준 균주는 Lactobacillus reuteri KCTC 3594 를 사용하였다. 또한 가축생균제용 유산균의 specific primer 확인을 위해 Lactobacillus plantarum KCTC3104을 사용하였으며, Lactobacillus 균주들의 배양을 위해 MRS (de Man, Rogosa and Sharpe) Agar (Difco) 배지를 사용하였으며, $37^{\circ} \mathrm{C}$ 에서 24시간 동안 혐기적으로 배양하였다.

\section{시험용 생균제}

본 시험에 사용된 생균제는 시중에서 판매되고 있는 유산균 배양 생균제를 구입하여 사용하였다. 가축용 생균제는 고체발 효(solid-state fermentation)방법을 통해 제조되었으며, 총 16 종의 생균제 제품을 본 시험에 사용하였다. 생균제 제조를 위 해 고체배지로서 탈지강에 규산염제 및 다공성 물질을 첨가하 였으며, 유산균 접종 후 $37^{\circ} \mathrm{C}$ 에서 $3 \sim 4$ 일 동안 고체 발효기에 서 제조한 제품을 사용하였다.

\section{생균수 측정}

생균수 측정을 위해 멸균 생리식염수 $9 \mathrm{ml}$ 에 시료 $1 \mathrm{~g}$ 을 넣은 후 10 진 희석하여 측정하였다. 유산균의 생균수 측정배 지는 MRS Agar (Lactobacillsu Agar acc. To De Man, Rogosa and Sharpe. Difco)를 사용하였으며, $37^{\circ} \mathrm{C}$ 에서 48 시간 동안 Anaerobic jar에 넣어 혐기배양한 후 균수를 측정하였다.

\section{Lactobacillus genus primer를 이용한 based-PCR}

$5 \%$ Chelex (Biorad, USA)를 사용하여 Lactobacillus 균주의 DNA를 추출하였고, 추출한 PCR template DNA의 16S-23S rRNA intergenic species region 을 Lactobacillus genus specific primer인 LbLMA-1 (forward), R16-1 (reverse)와 Lactobacillus genus Real-time PCR prime인 alllact-F (forward), alllact-R (reverse)를 사용하여 각각 증폭하였다(Table 1). Polymerase Chain Reaction은 DNA thermal cycler (Biorad, USA)를 이용 하였고, PCR 반응액은 template DNA $1 \mu \mathrm{l}, 2.5 \mathrm{mM}$ dNTPs $0.5 \mu \mathrm{l}, 1.25$ unit의 Taq polymerase (Takara) $0.125 \mu \mathrm{l}, \mathrm{PCR}$ buffer (15 mM MgCl2, $100 \mathrm{mM}$ Tris- $\mathrm{HCl} \mathrm{pH}$ 8.3, $500 \mathrm{mM}$ $\mathrm{KCl}) 2.5 \mu \mathrm{l}$ 와 $10 \mathrm{pmol}$ forward 및 reverse primer 각각 $1 \mu \mathrm{l}$ 를 넣은 후 최종 부피가 $25 \mu 1$ 가 되도록 멸균된 3차 증류수를 첨가 하였다. $\mathrm{PCR}$ 조건은 $94^{\circ} \mathrm{C}$ 에서 5 분간 실시 후, $94^{\circ} \mathrm{C}$ 에서 30 초, $58^{\circ} \mathrm{C}$ 에서 30 초, $72^{\circ} \mathrm{C}$ 에서 30 초, 33 cycle 수행하였으며 마지막 으로 $72^{\circ} \mathrm{C}$ 에서 10 분간 반응하였다. PCR 산물은 $2.0 \%$ agarose gel에서 전기영동하여 그 크기를 확인하였다.

\section{TA cloning 및 transformation}

증폭된 16S-23S rRNA intergenic species region PCR 산물 은 QIAquick ${ }^{\circledR}$ PCR purification kit (QIAGEN, Valencia, CA, USA)를 사용하여 정제한 후 PCR 생성물을 cloning하기 위하 여 Promega (USA)의 pGEM - T Vector Syste과 T\&A Cloning Vector (RBC Bioscience, KOREA)를 이용하였다. PCR 생성물 을 T vector protocol에 따라 ligation reaction [T4 DNA Ligase 10× Buffer $1 \mu \mathrm{l}$, pGEM - T vector (50 ng), PCR product $\times \mu l$, T4 DNA ligase (3 weiss units/ $\mu \mathrm{l}) 1 \mu \mathrm{l}$, add deionized water up to $10 \mu 1]$ 를 준비하여 상온에서 1 시간 반응시켰다. $-70^{\circ} \mathrm{C}$ 에 서 보관되어있는 E. coli Top10 competent cell $50 \mu 1$ 를 꺼내어 얼음에서 녹인 뒤 ligation을 실시한 반응물 $0.5 \mu \mathrm{l}$ 를 Micropulser (Biorad, USA)를 이용하여 electroporation 시킨 후 $500 \mu \mathrm{l} \mathrm{SOC} \mathrm{Medium}$ 을 첨가하여 $37^{\circ} \mathrm{C}$ 에서 1시간 배양 후 배양액을 ampicillin이 $50 \mu \mathrm{g} / \mathrm{ml}$ 농도로 첨가된 Lirua-Bertani agar배지에 도말하여 $37^{\circ} \mathrm{C}$ 에서 하루 동안 배양하였다. 이때 transformation의 color selection을 위하여 plate당 X-gal (bromo-4-chloro-3-indolyl- $\beta$-D-galacto-pyranoside, $20 \mathrm{mg}$ / $\mathrm{ml}) 35 \mu \mathrm{l}$, IPTG (isopropyl-1-thio- $\beta$-D-galactopyranoside, $20 \% \mathrm{w} / \mathrm{v}) 7 \mu 1$ 를 함께 첨가하였다. 배지 위에 형성된 white, blue colony 중에 white colony를 임의적으로 선택하여 다시 ampicillin $(50 \mathrm{mg} / \mathrm{ml})$ 이 포함된 LB Broth에 배양하였다.

\section{Plasmid DNA purification}

Solgent plasmid mini prep kit (Solgent, KOREA)를 사용하 여 plasmid DNA를 추출하였다. $5 \mathrm{ml}$ 의 배양액을 원심분리 하여 cell pellet을 얻은 후 $250 \mu \mathrm{l}$ 의 Buffer SP1으로 cell pellet

Table 1. Primer sets used in the experiment

\begin{tabular}{llcc}
\hline Primer & Sequence $\left(5^{\prime} \rightarrow 3^{\prime}\right)$ & PCR product size & Reference \\
\hline LbLMA1 (For) & $\begin{array}{l}\text { CTCAAAACTAAACAAAGTTTC } \\
\text { CTTGTACACACCGCCCGTCA }\end{array}$ & \multirow{2}{*}{$210 \mathrm{bp}$} & {$[8]$} \\
R16-1 (Rev) & TGGATGCCTTGGCACTAGGA & \multirow{2}{*}{$92 \mathrm{bp}$} & {$[18]$} \\
\hline Allact-F (For) & AAATCTCCGGATCAAAGCTTACTTTT & \\
Allact-R (Rev) & FAM-TATTAGTCCGTCCTTCATC-BHQ-1 plus & \\
Allact-P (Probe) & & \\
\hline
\end{tabular}


을 현탁 시킨다. $250 \mu$ l의 Buffer SP2를 넣고 4 6회 정도 부드 럽게 흔들어 혼합 후 $350 \mu \mathrm{l}$ 의 Buffer SGP3을 같은 방법으로 혼합하여 상온에서 10 분간 원심분리 하였다. Spin column을 $2 \mathrm{ml}$ collection tube에 장착시키고, 원심분리로 얻어진 상층액 을 장착된 spin column으로 옮긴 후 30 초간 $10,000 \mathrm{rpm}$ 으로 원심분리 하여 DNA를 얻었다. spin column에 $500 \mu \mathrm{l}$ 의 Buffer $\mathrm{WB}$ 를 넣고 원심분리하고, $750 \mu \mathrm{l}$ 의 Buffer WB를 넣고 원심분 리를 하였다. collection tube로 내려간 용액은 버리고 2분간 다시 한번 원심분리 한 후 30 50 $\mathrm{\mu l}$ 의 buffer $\mathrm{EB}$ 를 spin column의 membrane 중앙에 바로 떨어뜨린 후, 상온에서 1 분간 놓아둔 후에 원심분리 하여 정제된 DNA solution을 얻었다.

\section{Cloning 된 plasmid DNA copy number에 따른 detection limit}

Lactobacillus strain의 16S-23S rRNA intergenic species region이 cloning된 plasmid DNA를 확인한 후 Spectrophotometer (Hitachi, Japan)를 이용하여absorbance $260 \mathrm{~nm}$ 와 $280 \mathrm{~nm}$ 에 서 DNA 농도를 측정하였다. 각각의 농도를 이용하여 copy number를 계산하고, 10 진 희석법을 이용하여 $10^{10}$ copy부터 $10^{2}$ copy까지 희석하여 각 DNA 용액을 Real-time PCR 법을 통해 검출한계를 분석하였다.

$\mathrm{DNA}$ 농도=260 nm 흡광도 측정 값×희석비율 $(\%) \times \mathrm{DNA}$ 측정 상수 값(50)

Plasmid DNA copy number $=\left(\right.$ amount $\left.\times 6.022 \times 10^{23}\right) /$ (length $\times 1 \times 10^{9} \times 650$ )

\section{SYBR Green 1 방법을 이용한 RT PCR}

plasmid DNA의 농도를 결정한 후, 단계별로 희석 한 standard 샘플과 Wizard Genomic DNA purification kit (Promega, USA)를 이용하여 DNA를 추출한 생균제 제품을 Lactobacillus genus specific primer인 LbLMA-1 (reverse)와 R16-1 (forward)를 사용하여 증폭하였다. RT PCR 반응액은 template DNA $10 \mu \mathrm{l}$, Quantace (UK)사의 2x sensimix noref $25 \mu \mathrm{l}, 50 x$ SYBR $1 \mu \mathrm{l}, \mathrm{Mgcl} 2 \mu \mathrm{l}, 10 \mu \mathrm{M}$ forward 및 reverse primer 각각 $2 \mu 1$ 를 넣은 후 최종 부피가 $50 \mu 1$ 가 되도록 멸균된 3차 증류수를 첨가하여 Chromo4 Detector (Bio-Rad)에 반응시 켰다. Real-time PCR 조건은 $95^{\circ} \mathrm{C}$ 에서 15 분간 실시 후, $95^{\circ} \mathrm{C}$ 에 서 15 초, $57^{\circ} \mathrm{C}$ 에서 15 초, $72^{\circ} \mathrm{C}$ 에서 30 초를 35 cycle 수행하였으 며 마지막으로 $72^{\circ} \mathrm{C}$ 에서 5 분간 반응하였다. Ct (threshold) 값 은 형광커브와 역치선이 만나는 cycle 값으로 $\mathrm{MJ}$ opticon monitor (Bio-rad)로 분석하였다.

\section{Probe 방법을 이용한 RT PCR}

plasmid DNA의 농도를 결정한 후, 단계별로 희석 한 standard 샘플과 Wizard Genomic DNA purification kit (Promega, USA)를 이용하여 DNA를 추출한 생균제 제품을 Lactobacillus genus RT PCR primer인 alllact-F (forward)와 alllact-R (reverse), alllact-P (probe)를 사용하여 증폭하였다. Real-time PCR 반응액은 template DNA 10l, Quantace (UK) 사의 $2 x$ sensimix noref $25 \mu \mathrm{l}$, probe $2 \mu \mathrm{l}$, Mgcl $1 \mu \mathrm{l}, 5 \mu \mathrm{M}$ forward 및 reverse primer 각각 $2 \mu \mathrm{l}$ 를 넣은 후 최종 부피가 $50 \mu 1$ 가 되도록 멸균된 3차 증류수를 첨가하여 Chromo4 Detector (Bio-Rad)에 반응시켰다. Real-time PCR 조건은 $95^{\circ} \mathrm{C}$ 에서 10 분간 실시 후, $95^{\circ} \mathrm{C}$ 에서 15 초, $60^{\circ} \mathrm{C}$ 에서 45 초, $72^{\circ} \mathrm{C}$ 에서 30 초를 $45 \mathrm{cycle}$ 수행하였으며 마지막으로 $72^{\circ} \mathrm{C}$ 에서 30 초간 반응하였다. Ct (threshold) 값은 형광커브와 역치선이 만나는 cycle값으로 MJ opticon monitor (Bio-rad)로 분석하였다 (Table 2).

\section{결과 및 고찰}

\section{Lactobacillus genus primer를 이용한 based-PCR}

일반적인 $\mathrm{PCR}$ 에 사용되는 특이 primer는 real-time $\mathrm{PCR}$ 을 수행하기에는 PCR 산물크기가 커서 PCR efficency를 떨어뜨 리기 때문에 DNA정량에 오류로 작용할 가능성이 있으며[12], 따라서 PCR 산물의 크기가 작은 primer를 사용하였으며, target DNA 이외의 비특이적인 band가 나타나는지를 확인하였 다. Lactobacillus genus specific primer인 LbLMA- 1 (reverse) 과 R16-1 (forward), Lactobacillus genus RT PCR prime인 alllact-F (forward)와 alllact-R (reverse)의 PCR 산물을 2.0\% agarose gel에서 $100 \mathrm{~V}$ 에서 40 분간 전기 영동하여 확인한 결과 Lactobacillus genus specific primer의 Amplification size는 210 bp, Lactobacillus genus Real-time PCR primer의 Amplification size는 $92 \mathrm{bp}$ 임을 확인 할 수 있었으며, 비특이 적인 band는 나타나지 않았다(Fig. 1).

Lactobacillus reuteri 16S-23S rRNA intergenic species region의 cloning

LbLMA-1과 R16-1 primer set을 이용하여 증폭시킨 DNA fragment가 $210 \mathrm{bp}$ 임을 확인하고 pGEM-T vector system (promega, USA)을 이용하여 형질 전환 하였다. plasmid DNA (vector size 3,015 bp)의 크기가 약 $3.2 \mathrm{~kb}$ 정도임을 확인하고 (Fig. 2), plasmid를 추출 및 정제하여, Macrogen에 DNA

Table 2. Real-time PCR standard curve using the $\mathrm{R}^{2}$ and slope

\begin{tabular}{lccc}
\hline & Method & $\mathrm{R}^{2}$ & Slope \\
\hline Lactobacillus reuteri & SYBR Green1 method & 0.99 & -3.346 \\
Lactobacillus reuteri & Probe method & 0.99 & -3.321 \\
\hline
\end{tabular}



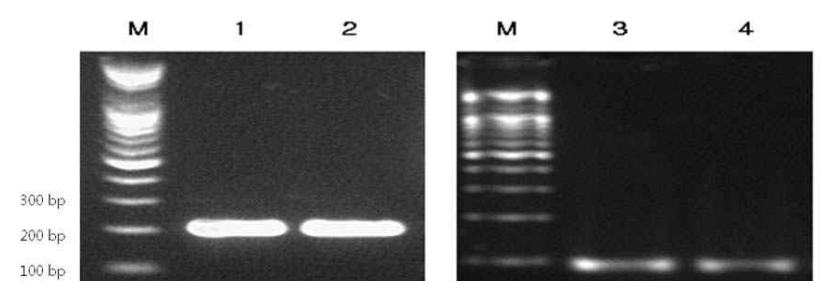

Fig. 1. PCR amplification of Lactobacillus genomic DNA with various specific primer sets. M: size marker (100 bp), Lane 1: LbLMA-1 \& R16-1 (L.reuteri), Lane 2: LbLMA-1 \& R16-1 (L.plantarum), Lane 3: allact-F \& alllact-R (L.reuteri), Lane 4: alllact-F \& alllact-R (L.plantarum)

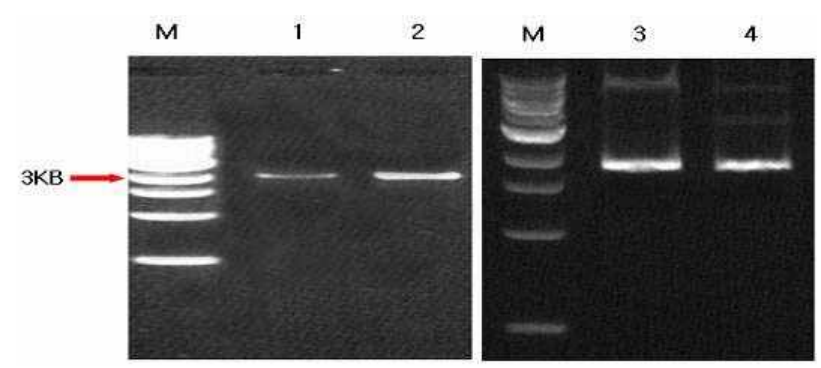

Fig. 2. Identification of plasmid DNA by agarose gel electrophoresis. M: size marker $(1 \mathrm{~kb})$, Lane 1 : pGEM-T vector/ Lreuteri, Lane 2: pGEM-T vector/ L.plantarum, Lane 3: T\&A Cloning vector/ Lreuteri, Lane 4: T\&A Cloning vector/ L.plantarum

sequence를 의뢰하였다. sequence된 염기서열을 가지고 plasmid DNA가 insert 되었는지 확인하기 위해서 Finch TV program과 BLAST (Basic Local Alignment Search Tool) search program을 이용하여 NCBI (National Center for Biotechnology Information)의 Genebank에서 염기서열을 비 교한 결과 $99 \%$ 일치함을 알 수 있었다. alllact-F와 alllact-R primer set을 이용하여 증폭시킨 DNA fragment가 $92 \mathrm{bp}$ 임을 확인하고 T\&A Cloning vector (RBC Bioscience, Korea)을 이 용하여 형질 전환 하였다. plasmid DNA (vector size $2728 \mathrm{bp}$ ) 의 크기가 약 $2.8 \mathrm{~kb}$ 정도임을 확인하고, plasmid DNA를 추출 및 정제하였다.

Gene cloning 된 plasmid DNA copy number에 따른 검출한계

plasmid DNA를 $10^{10}$ copy number로부터 $10^{2}$ copy number에 이르기 까지 단계적으로 희석하여 SYBR Green1 dye를 이용하여 RT PCR을 실행한 결과 $\mathrm{Ct}$ 값에 따른 plasmid DNA copy number의 표준곡선을 얻었으며 이때의 Slope는 -3.346 이었고, $\mathrm{Y}$ 절편은 33.18, $\mathrm{R}^{2}$ 값은 0.993으로 나타났다(Fig. 3). Probe 방법을 이용하여 Real-time PCR을 실행한 결과 Slope 는 -3.321이었고, Y절편은 39.10, $\mathrm{R}^{2}$ 값은 0.995로 나타났다(Fig. 4). 두 가지 방법 모두 $10^{10}$ copy number 이상에서는 초기

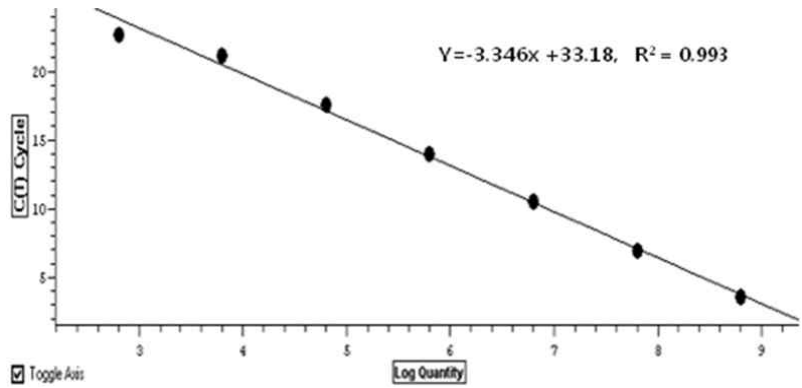

Fig. 3. Standard curve for the copy number of plasmid DNA containing Lreuteri 16S-23S rRNA intergenic species region gene using SYBR Green 1 method.

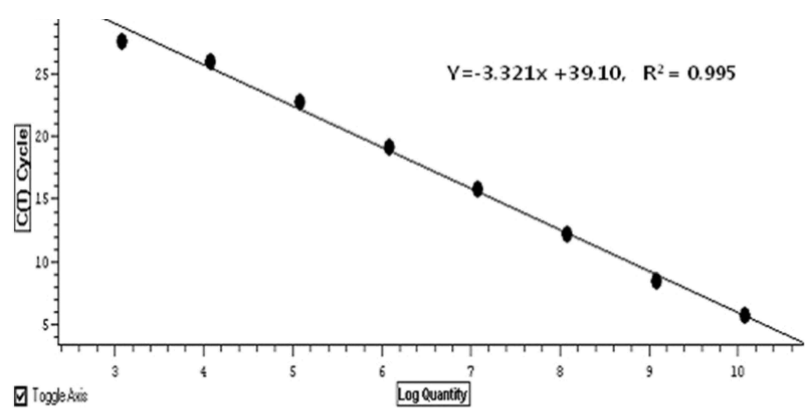

Fig. 4. Standard curve for the copy number of plasmid DNA containing Lreuteri 16S-23S rRNA intergenic species region gene using Probe method.

$\mathrm{DNA}$ 양이 많아 PCR inhibitor로 작용하여 검출곡선을 나타낼 수 없었다. SYBR Green1 dye를 이용한 방법과 Probe 방법을 이용한 plasmid DNA copy nember에 대한 차이는 없는 것으 로 사료되며, 이를 이용한 표준곡선 제작 또한 가능함을 알 수 있었다.

RT PCR system을 이용한 Lactobacilli 정성.정량 분석

$\mathrm{RT} \mathrm{PCR}$ 의 정량에서 가장 중요한 개념은 crossing point 혹 은 Ct (Threshold Cycle) Value 이라는 수치이다. Fluorescence값이 base line값을 지나는 시점을 의미하므로 그 절대값이 낮을수록 sample내 존재하는 미생물 균총의 수가 많음을 의미하게 된다[11].

SYBR Green1 방법을 이용한 생균제의 Lactobacilli 정성·정 량 분석결과 16 개의 제품에서 모두 증폭이 일어났으며, 이때 Real-time PCR값은 4.46 6.56 log copies로 나타났고, 생균수 측정 결과 값은 5.63 7.59 $\log \mathrm{CFU} / \mathrm{g}$ 로 나타나 차이를 보였 다(Table 3). Probe 방법을 이용한 생균제의 Lactobacilli 정성. 정량 분석결과에서는 Real-time PCR값은 5.51 7.00 log copies로 나타났으며, 생균수 측정 결과 값은 5.63 7.59 log $\mathrm{CFU} / \mathrm{g}$ 로 나타나 차이를 보였다(Table 4). PCR inhibitor와 primer의 dimer형성에 의한 conventional method와 차이가 있음을 확인 할 수 있었다[6]. 하지만 SYBR Green1 방법과 Probe 방법을 이용한 Lactobacilli 정성·정량 분석결과 표준곡 
Table 3. Quantitative analysis of Lactobacilli species as probiotics using Real-time PCR by SYBR Green 1 method

\begin{tabular}{cccc}
\hline Treat. & $C(t)$ & $\begin{array}{c}\text { Real-time assay } \\
(\log \text { copies })\end{array}$ & $\begin{array}{c}\text { Plate count } \\
(\log C F U / g)\end{array}$ \\
\hline 1 & 12.82 & 6.04 & 5.96 \\
2 & 12.07 & 6.26 & 5.87 \\
3 & 13.47 & 5.84 & 5.86 \\
4 & 14.56 & 5.52 & 6.06 \\
5 & 12.00 & 6.28 & 6.10 \\
6 & 13.53 & 5.83 & 5.97 \\
7 & 18.12 & 4.46 & 6.03 \\
8 & 11.06 & 6.56 & 6.06 \\
9 & 11.62 & 6.40 & 5.63 \\
10 & 16.12 & 5.05 & 7.44 \\
11 & 13.40 & 5.86 & 7.40 \\
12 & 13.29 & 5.90 & 7.59 \\
13 & 11.95 & 6.30 & 7.33 \\
14 & 11.28 & 6.50 & 7.01 \\
15 & 13.12 & 5.95 & 6.62 \\
16 & 11.25 & 6.51 & 6.53 \\
\hline
\end{tabular}

Table 4. Quantitative analysis of Lactobacilli species as probiotics using Real-time PCR by Probe method

\begin{tabular}{cccc}
\hline Treat. & $C(t)$ & $\begin{array}{c}\text { Real-time assay } \\
(\log \text { copies })\end{array}$ & $\begin{array}{c}\text { Plate count } \\
(\log \text { CFU } / g)\end{array}$ \\
\hline 1 & 20.89 & 5.79 & 5.96 \\
2 & 21.32 & 5.66 & 5.87 \\
3 & 21.84 & 5.51 & 5.86 \\
4 & 22.11 & 5.43 & 6.06 \\
5 & 19.94 & 6.06 & 6.10 \\
6 & 20.91 & 5.78 & 5.97 \\
7 & 20.99 & 5.76 & 6.03 \\
8 & 18.97 & 6.34 & 6.06 \\
9 & 19.98 & 6.05 & 5.63 \\
10 & 21.60 & 5.58 & 7.44 \\
11 & 19.58 & 6.17 & 7.40 \\
12 & 19.66 & 6.15 & 7.59 \\
13 & 18.09 & 6.60 & 7.33 \\
14 & 16.83 & 6.97 & 7.01 \\
15 & 21.57 & 5.59 & 6.62 \\
16 & 16.74 & 7.00 & 6.53 \\
\hline
\end{tabular}

선 도출에는 차이가 없었으나, 혼합 미생물이 포함되어 있는 시료분석에서 Probe 방법을 이용한 분석방법이 생균수 측정 결과값과 근사함을 알 수 있었다. 또한 생균수 측정결과 값이 RT PCR 기법을 이용하여 측정한 미생물 수 보다 높음을 알 수 있었다. 이는 RT PCR기법은 미생물의 특이적인 primer를 이용하여 특이적 strain을 분석해내는 반면에 생균수 측정방 법은 특이적 genus에 대한 전체적인 미생물을 측정하기 때문 으로 사료된다[12].

이러한 결과를 종합해 볼 때 본 연구에서 실시한 RT PCR법 은 3 4일이 소요되는 기존의 배지법과 비교하여 24시간 이내
에 신속하게 검출이 가능하다고 여겨지며, 또한 RT PCR을 이용한 분석방법에서도 dye 사용과 primer 사용에 따라 결과 값이 차이가 나타났음을 확인 할 수 있었으며, Probe 방법을 이용하여 실험 한 결과가 민감한 결과를 나타내었음을 확인 할 수 있었다.

\section{감사의 글}

본 논문은 농촌진흥청 공동연구사업(과제번호PJ006935)지 원에 의해 이루어진 것임.

\section{References}

1. Annuk, H, J. Shchepetova, T. Kullisaar, E. Songisepp, M. Zilmer, and M. Mikelssar. 2003. Characterization of intestinal Lactobacillus as probiotics candidates. J. Appl. Microbiol. 94, 403-412.

2. Berg, R. D. 1998. Probiotics, prebiotics or conbiotics. Trends Microbiol. 6, 89-92.

3. Bohaychuk, V. M., G. E. Gensler, M. E. McFall, R. K. King, and D. G. Renter. 2007. A real-time PCR assay for the detection of Salmonella in a wide variety of food and food animal matrices. J. Food Protect. 70, 1080-1087.

4. Catarame, T. M. G., K. A. O'Hanlon, D. A. McDowell, I. S. Blair, and G. Duffy. 2006. Comparison of a real-time polymerase chain reaction assay with a culture method for the detection of Salmonella in retail meat samples. J. Food Safety 26, 1-15.

5. Cheung, P. Y., K. K. Kwok, and K. M. Kam. 2007. Application of BAX system, Tecra Unique TM Salmonella test, and a conventional culture method for the detection of Salmonella in ready-to-eat and raw foods. J. Appl. Microbiol. 103, 219-227.

6. Choi, J. P. 2005. Quantitative analysis by Real-time PCR and Physiological properties of Food-borne Pathogens. Kyeong-won univ. 55.

7. Conway, P. L., S. L. Gorbach, and B. R. Coldin. 1987. Survival of lactic acid bacteria in the human stomach and adhesion to intestinal cells. J. Daily Sci. 70, 1-12.

8. Dubernet, S., N. Desmasures, and M. Gueguen. 2002. A PCR-based method for identification of Lactobacilli at genus level. FEMS Microbiol. Lett. 214, 271.

9. Han, S. R., J. Y. Hyeon, H. Y. Kim, J. S. Park, H. S. Shin, and K. H. Seo. 2008. Evaluation of conventional culture methods and validation of immunoassays for rapid detection of Listeria monocytogenes in daily and processed foods. Korean J. Food Sci. Ani. Resour. 286, 16-622.

10. Hein, I., G. Flekna, M. Krassnig, and M. Wagner. 2006. Real-time PCR for the detection of Salmonella spp. In food: An alternative approach to a conventional PCR system suggested by the Food-PCR project. J. Microbiol. Methods 66, 538-547.

11. Higuchi, R., C. Fockler, G. Dollinger, and R. Waston. 1993. 
Kinetic PCR: Real monitoring of DNA amplication reactions. Biotechnology 11, 1026.

12. Kim, Y. Y. Study for nutrition diarrhea prevention in weaning pigs by controlling intestinal microflora. Ministry for food, agriculture, forestry and fisheries. Research paper. 38.

13. Korean Feed Processing. Subsidiary feeder guideline. Attach documents 3.

14. Krascsenicsova, K., L. Piknova, E. Kaclikova, and T. Kuchta. 2008. Detection of Salmonella enteric in food using two-step enrichment and real-time PCR. Lett. Appl. Microbiol. 46, 483-487.

15. Lee, E. Y. 2008. Problems and verification system of probiotics as livestock-enviroment improving agent produced. Korean J. Microbiol. Biotechnol. 36, 87-95.

16. Lee, T. S., B. K. Park, and D. H. Oh. 2003. Detection of pathogenic Yersinia Enterocolitica in drinking water and vegetables by multiplex PCR. J. Korean Soc. Food Sci. Nutr. 32, 35-41

17. Malorny, B., E. Paccassoni, P. Fach, C. Bunge, A. Martin, and R. Helmuth. 2004. Diagnostic real-time PCR for detection of Salmonella in food. Appl. Environ. Microbiol. 70, 7046-7052.

18. Monique, H. and K. Jan. 2006. Quantitative Real-time PCR analysis of fecal Lactobacillus species in infants receiving a prebiotic infant formula. Appl. Environ. Microbiol. 72, 2359-2365.

19. Paik, H. D., M. Y. Jung, H. Y. Jung, W. S. Kim, and K. T. Kim. 2002. Characterization of Bacillus polyfermenticus SCD for oral Bacteriotherapy of Gastrointestinal Disorders. Korean J. Food Sci. Technol. 34, 73-78.

20. Palomares, C., M. J. Torres, A. Torres, J. Aznar, and J. C. Palomares. 2003. Rapid detection and identification of Staphylococcus aureus from blood culture specimens using real-time fluorescence PCR. Diagn. Microbiol. Infect. Dis. 45, 183-189.

21. Uyttendaele, M., K. Vanwildemeersch, and J. Debevere. 2003. Evaluation of real-time PCR vs automated ELISA and a conventional culture method using a semi-solid medium for detection of salmonella. Lett. Appl. Microbiol. 37, 386-391.

22. Yeh, K. S., C. E. Tsai, S. P. Chen, and C. W. Liao. 2002. Comparison between VIDAS automatic enzyme-linked fluorescent immunoassay and culture method for Salmonella recovery from pork carcass sponge samples. J. Food Protect $65,1656-1659$

\section{초록 : Real-time PCR을 이용한 가축생균제용 유산균 정량분석}

최연재 $\cdot$ 김선호 $\cdot$ 구민정 $\cdot$ 최한나 $\cdot$ 김동운 $\cdot$ 조상범 ${ }^{3} \cdot$ 김수기 ${ }^{3} \cdot$ 전체옥 ${ }^{4} \cdot$ 배귀석 ${ }^{5} \cdot$ 이상석*

(순천대학교 동물자원과학과, ${ }^{1}$ 순천대학교 생물학과, ${ }^{2}$ 농촌진흥청 국립축산과학원, ${ }^{3}$ 건국대학교 동물생명과 학부, ${ }^{4}$ 중앙대학교 생명과학과, ${ }^{5}$ 중앙대학교 동물자원과학과)

본 연구는 가축생균제용 유산균을 Real-time PCR정량분석법을 이용하여 분석하였다. SYBR Green1 방법과 Probe 방법을 이용하여 표준곡선을 제작한 결과, SYBR Green1 방법에서는 Slope 값이 -3.346이었고, Y절편은 $33.18, R^{2}$ 값은 0.993 으로 나타났으며, Probe 방법에서는 Slope값이 -3.321이었고, Y절편은 39.10, $R^{2}$ 값은 0.995 로 나타나, 이를 이용한 표준곡선 제작이 가능함을 알 수 있었다. SYBR Green1 방법을 이용한 생균제의 Lactobacilli 정성·정량 분석결과 Real-time PCR값은 4.46 6.56 log copies로 나타났고, 생균수 측정 결과 값은 $5.63 \sim 7.59 \log$ $\mathrm{CFU} / \mathrm{g}$ 로 나타났으며, Probe 방법을 이용한 생균제의 Lactobacilli 정성·정량 분석결과에서는 Real-time PCR 값은 5.51 7.00 log copies로 나타났으며, 생균수 측정 결과 값은 5.63 7.59 log CFU/g로 나타났다. 본 연구에서 실시 한 RT PCR법은 3 4일이 소요되는 기존의 배지법과 비교하여 24시간 이내에 신속하게 검출이 가능하다고 여겨 지며, 또한 RT PCR을 이용한 분석방법에서도 dye 사용과 primer 사용에 따라 결과값이 차이가 나타났음을 확인 할 수 있었으며, Probe 방법을 이용하여 실험 한 결과가 민감한 결과를 나타내었음을 확인 할 수 있었다. 